\title{
The Research of E-government on Big Data in China
}

\author{
WEI LU \\ The Communication University of China, Chaoyang Distinct, Beijing, China \\ luwei@cuc.edu.cn
}

\begin{abstract}
Keywords: E-government, Big Data, Information and Communication Technologies (ICTs) Abstract. E-government is a useful way to facilitate the daily administration of government in order to deliver services and engage people in decision-making processes. In this paper, according to the situation of Chinese e-government ,the author analyzes the main role and development of Chinese e-government and the main challenges, and finally based on Big Data analyzes the trend of Chinese e-government.
\end{abstract}

\section{Introduction}

In recent decades, e-government initiatives have been spread all over the world. Countries in all regions are increasingly accepting people who innovate and make use of information and communication technology (ICT) to provide services and participate in the decision-making process.

In this paper, the author first analyzes the main role of e-government (section 1), then analyzes the current situation of Chinese e-government development (section 2) and the main challenges (section 3), and finally based on Big Data analyzes the trend of Chinese e-government(section 4).

\section{The benefits of E-Government}

First of all, the benefits of e-government are manifold, and scholars continue to assess its impact on a range of areas of public administration and policy. The e-government can expand democracy by supporting the democratic process. It is likely to increase transparency and government responsibility.

Second, the benefits include improving administrative efficiency, government response, increasing government trust and reducing corruption. Although it is concerned that it may strengthen existing structural inequalities, e-government may also mobilize and provide voices to those who are usually underrepresented in the decision-making process. The E-government has potential citizen participation in solving the problem of evil, and in doing so creates partnerships between citizens and their governments. That is to say, e-government is no longer mainly focused on the use of information and communication technology to provide information and anticipation, and information acquisition will make more active citizens.

Finally, as the development of information and communications technology has allowed more interaction and dialogue, the role of citizens in $\mathrm{E}$ - government has shifted from the information consumer to the common producer of knowledge resulting in what Linders (2012) calls we-government.

\section{The Situation of E-Government in China}

In China, with the development of government websites, officials and citizens realize that the value of the Internet serves as another channel for citizens to make use of it. Citizens are required to complete the government's requests online without having to go to specific locations to complete paperwork. Electronic transactions provide higher efficiency for customers and agents, not just cataloguing information. Moreover, this capability provides an opportunity to interact with the wider democratic process and interact with those who are composed. Reluctantly or unable to attend public hearings.

There is no doubt that full-featured e-government will make service delivery more efficient and increase the savings of government and citizens. The electronic government, as a revolutionary entity, has changed the way people interact with the government, and gives citizens the time to deal with 
their governments at any time, save time for paperwork, inconvenience to government agencies, and wait in line.

China has made great progress as a developing country in the development of e-government over the past two decades. With the fast development of e-government in China since 1999, governments at all levels have started to build their websites for information provision and service delivery. By 2015, it is covering $100 \%$ of government sectors at the national level, $100 \%$ of governments at the province level, $99.1 \%$ at the city level, and more than $85 \%$ at the county level with around 58,000 government websites. Local governments in China have increasingly been making greater use of mobile apps to provide for more convenient services. In addition, various city governments utilized big data to promote policy-making and have implemented strategies to develop e-government. (Li Deren et al.,2015)

\section{Challenges and Solutions in the Implementation of E-Government in China}

\section{Government}

China lacks projects, has unrealistic goals, and lacks organizational goals. Offline processes need to be integrated before they are online, and the focus of projects and online services should be from the user's perspective to respond to local needs.

These limitations are conducive to the lack of control mechanisms and vision. Coordination between government departments leads to efficiency problems and restricts participation processes. Moreover, lack of cooperation within the government and interdepartmental incompatibility are conducive to the implementation of a rigid structure which discourages public debate and open concept.

In addition, the lack of support from major public leaders may be reflected in the lack of appropriate government ICT policy formulation to promote the dissemination of information, the correct planning of the adoption and diffusion of the infrastructure of the ICT development network, and the stimulation of IMPR.

To solve this problem, governments should establish an organization for planning, monitoring, implementing and controlling e - government development projects, making necessary short-term and long-term plans, including expected expenditure, income flow and duration. At the same time, these circumstances compel the public administration to continue to provide basic services through multiple channels in the short term to avoid the exclusion of those who are not online.

\section{Technologies}

Development requires the establishment of a cross system network system, network, software (free software or open source), hardware and organization, which is important in the early stages of the implementation of $\mathrm{E}$ - government units, because the success of $\mathrm{E}$ - government requires a well-defined and well-formulated, forward-looking and system-thinking, strategy and the implementation of that strategy.

All this means that the implementation of the new technology, the framework of e-government, the innovation of the public sector, and the decrease in the flexibility of the organization and the flexibility of the organization have hindered the advantages provided by the electronic government to the citizens.

In addition, technical incompatibility, complexity, new technology, lack of ICT technical skills and experience, and security issues are potential challenges that may affect the development of e-government.

Therefore, it is suggested that government departments and entities develop systematic thinking to deal with key issues of e-government development, such as electronic integration and quality, and strategic planning within three to five years. It is not only to hold training courses, but also to be taught by professionals and scholars both at home and abroad, but also to have a strategy for national policies and programmes to be trained in human capital. 


\section{Institutional and Organizational}

The organization and management structure did not support the implantation, appropriate, coordination and evolution of E - government initiatives, which could lead to the use of incorrect information and communication technologies. Therefore, it is wise to implement public infrastructure so that all governments can use them.

The implementation of these initiatives should have appropriate agents, starting from the project implementation, allowing the definition of the project, negotiating with the staff to facilitate the careful preparation of the project, and the choice of the best qualified contractor. All stages of project implementation will be encouraged.

\section{Citizens' Acceptance}

The limitation of access to the Internet is mainly due to the lack of telecommunications infrastructure in China. Moreover, the population is short of education and the illiteracy rate is high. Therefore, governments must establish telecommunications infrastructure in their own countries, promote the popularization of information and communication technology, reduce the price of Internet access and access to services related to the liberalization of telecommunications services.

In terms of human resources, any resistance to the new ICT initiative should be eliminated through training and incentives. In this sense, managers should provide an environment for encouraging employees to use new technologies, to identify the benefits of their use and to their impact on their work, to try to reduce the resistance of employees to the use of information and communication technology and to resist any negative attitude.

\section{Application of Big Data in E-Government}

\section{Big Data and E-Government}

Big data applications have potential to serve many departments of e-government. It helps to provide better customer experience and services to help enterprises achieve better performance (E.g. G. higher profits or increased market share). Transport systems can greatly benefit from big data, optimize routes and schedules, adapt to different needs, and be more environmentally friendly. Deploying big data applications requires a good support for information and communication technology (ICT) infrastructure. ICT supports e-government because it provides useful solutions and unique solutions. Without it, it may not be possible. For example, it provides a simple way to deal with services from different fields / locations to reduce transportation costs and achieve effective transportation planning. In general, e-government can be smarter when using ICT and big data for many applications and services.

In the past two years, $90 \%$ of the world's digital data have been captured. Therefore, many governments have begun to use big data to support the development and sustainability of e-government around the world. Through the realization of the main characteristics of e-government, the standards, principles and requirements of urban e-government application are maintained. These characteristics include sustainability, resilience, governance, quality of life, and intelligent management of natural resources and urban facilities. E - government has clearly defined components, such as mobility, governance, environment and people, and its applications and services, such as medical, transportation, intelligent education and energy. In order to facilitate such applications and services, a lot of computing and storage facilities are needed. One way to provide such a platform is to rely on cloud computing and make use of the many advantages of cloud services to support E-government's big data management and application. Through the use of these technologies, e-government is more likely to be smarter, more effective and more effective in achieving their goals than ever before.

\section{The Benefit of Big Data in E-Government}

At present, many cities are competing to become e-government, hoping to gain some benefits in terms of economy, environment and society. Therefore, we may take advantage of big data analysis in e-government applications to get possible opportunities. Therefore, some advantages and 
opportunities may help to make decisions or redesign cities into e-government. With such a decision, it is possible to achieve sustainability, adaptability and improvement in governance. In addition to improving the quality of life of citizens and introducing intelligent management of infrastructure and natural resources. Some of the benefits of $\mathrm{E}$ - government include:

1. Better quality of life: better service, more efficient work and life patterns, and less waste (time and resources), e - government citizens will have a better quality of life. It is better to plan life / work space and place, more efficient transportation systems, better and faster services, and provide sufficient information to make wise decisions.

2. The higher the transparency and openness: the need for better management and control of the relationship between E-government and large data, the different aspects and applications of e-government will promote the development of interoperability and openness to a higher level. Data and resource sharing will be normal. In addition, this will increase information transparency for everyone. This will encourage collaboration and communication among entities, and create more services and applications to further strengthen e-government. An example is the United States government's collection and dissemination of transparency and openness in the name of extensive data, publications and content. This provides an effective opportunity for citizens and government entities to exchange and use data.

These benefits will require high level of complexity and participation in applications, resources and people involved. Opportunities to achieve these benefits are available.

\section{Conclusions}

The main challenge of implementing E-government in China is a lack of well planned strategic planning. In this sense, the Chinese government should understand the potential for information technology to change in areas beyond the introduction of structural tools. They are faced with great difficulties, the development of technical ability, the allocation of sufficient financial resources and the adjustment of the corresponding institutional environment, a systematic way of thinking can help China to successfully implement the ICT. The implementation of big data in e-government is a new trend in China.

\section{Acknowledgements}

This project is supported by the Research and Cultivation and Foundation of Communication University of China.

\section{References}

[1] Aladalah, M., Cheung, U., Lee, V. C. S., \& Alamri, S. (2017). Public value co-creation via Gov 2.0 complexity cube. In L. Alcaide Muñoz \& M. P. Rodríguez Bolívar (Eds.), International e-Government development policy, implementation and best practices. Basingstoke: Palgrave Macmillan. forthcoming.

[2] Moon, M. J. (2002). The evolution of e-government among municipalities: Rhetoric or reality? Public Administration Review, 62(4), 424-433..

[3] LI De Ren, CAO Jian Jun, YAO Yuan, Big data in smart cities, Information Sciences ( 2015), Vol. 58 108101:1-108101:12 doi: 10.1007/s11432-015-5396-5

[4] Linders, D. (2012). From e-government to we-government: Defining a typology for citizen coproduction in the age of social media. Government Information Quarterly, 29(4), 446-454.

[5] Musso, J., Weare, C., \& Hale, M. (2000). Designing web technologies for local governance reform: Good management or good democracy? Political Communication, 17(1), 1-19. doi:10.1080/105846000198486. 